\section{Na costura do sapato, o desmanche das operárias: estudo das condições de trabalho e saúde das pespontadeiras da indústria de calçados de Franca, São Paulo, Brasil}

\author{
Shoes stitched, workers unstitched: a study on \\ working and health conditions among women \\ factory workers in the footwear industry in \\ Franca, São Paulo State, Brazil
}

\author{
${ }^{1}$ Faculdade de Medicina de \\ Ribeirão Preto, Universidade \\ de São Paulo, Ribeirão Preto, \\ Brasil. \\ 2 Faculdade de Filosofia, \\ Ciências e Letras de Ribeirão \\ Preto, Universidade de São \\ Paulo, Ribeirão Preto, Brasil. \\ Correspondência \\ V. L. Navarro \\ Faculdade de Filosofia, \\ Ciências e Letras de Ribeirão \\ Preto, Universidade de São \\ Paulo. \\ Av. Bandeirantes 3900, \\ Ribeirão Preto, $S P$ \\ 14049-901, Brasil. \\ vnavarro@usp.br
}

\begin{abstract}
This study aimed to analyze associations between working conditions and health problems reported by women workers assigned to mechanical stitching in the footwear industry in Franca, São Paulo State, Brazil. The qualitative study's theory and methodology were based on historical and dialectical materialism and combined sociological and ethnographic research techniques. Data were collected with taped interviews, focusing on the workers' life and work stories, systematic observation of the work process, consultation of historical documents, and imagistic production. Analysis of the data revealed the effects of work in mechanical stitching on the health of women workers employed in the factory and at home, who experience precarious labor conditions involving workday intensification and extension, preset production targets, job insecurity, and unhealthy workplaces.
\end{abstract}

Occupational Health; Working Women; Working Conditions
Taísa Junqueira Prazeres 1

Vera Lucia Navarro 2

\section{Introdução}

Nas últimas décadas, o mundo do trabalho foi palco de grandes transformações organizacionais e tecnológicas que modificaram os processos e as relações de trabalho, o que resultou em novas formas de organização da produção, na adoção de novas tecnologias, na precariedade das relações de trabalho, na terceirização, na subcontratação e na ampliação da jornada de trabalho, dentre outras. Tais mudanças contribuíram para o aumento das doenças e dos acidentes relacionados ao trabalho.

Essas transformações que modificaram o mundo do trabalho e a própria classe trabalhadora se constituíram em processo destrutivo no qual é possível constatar a “...redução do proletariado industrial, fabril, tradicional, manual, estável e especializado, herdeiro da era da indústria verticalizada do tipo taylorista e fordista" 1 (p. 336).

O modelo japonês ou toyotista que, no Brasil, vinha se reproduzindo desde o início dos anos de 1980 por conta da adoção de novas formas de organização do trabalho, do atendimento às necessidades de flexibilidade da produção e se adequando à lógica de acumulação capitalista, intensificou-se a partir da década de 1990 e contribuiu decisivamente para expandir a precariedade do trabalho. Foi observada a redução dos quadros de funcionários das empresas decor- 
rente da externalização de partes do processo de produção, realizada por terceiros, o que eliminou postos de trabalho e resultou em desemprego para contingentes significativos de trabalhadores.

No bojo dessas mudanças, verificou-se crescimento significativo do trabalho feminino que, em muitos países avançados, é responsável por mais de $40 \%$ da força de trabalho. O trabalho feminino foi absorvido pelo capital particularmente no universo de trabalho precário, part-time, informal, desregulamentado; a tais mazelas adicionam-se a desigualdade salarial, contraditória à sua participação no mercado de trabalho e à desigualdade dos direitos sociais e trabalhistas. Repercute ainda o fato de que na divisão sexual do trabalho pelo capital no espaço fabril, as atividades de capital intensivo são exercidas predominantemente por homens e, às mulheres, são destinadas atividades mais rudimentares, menos qualificadas e de trabalho mais intenso 2. Hirata 3 afirmou que no processo de reestruturação produtiva os postos de trabalho que implicam tarefas repetitivas são os mais disponíveis para as mulheres.

Dentre as muitas consequências da nova divisão sexual do trabalho, pode-se afirmar que o crescimento do trabalho feminino é caracterizado pelo trabalho mais precário, de menor salário, jornada mais prolongada em relação aos homens e fortemente marcado pela informalidade ${ }^{2}$, situação que resulta em graves implicações à vida e à saúde das trabalhadoras.

O desmonte do mercado formal de trabalho provocado pela avalanche da terceirização dificultou não apenas a fiscalização dos ambientes de trabalho, mas a própria identificação das doenças ali originadas 4 . Mesmo assim, ocorreu nos últimos anos aumento significativo do número de queixas e sintomas relacionados às precárias condições de trabalho, o que intensificou o processo de adoecimento que atinge, sobretudo, a classe trabalhadora feminina e resultou no crescente número de trabalhadoras com fadiga, déficits auditivos e visuais, transtornos de ansiedade, intoxicações exógenas e outras doenças como as lesões por esforços repetitivos (LER/DORT) 5 .

Os agravos à saúde do trabalhador não se limitam ao espaço da produção e atingem todas as esferas da vida privada 6 , pois o adoecimento representa um rompimento na vida cotidiana e modifica os projetos de vida e as relações sociais.

Este artigo remete a esse debate, considerando que essa problemática é verificada nas indústrias de calçados de Franca, São Paulo, Brasil, que, a partir da década de 1990, intensificaram o processo de reestruturação produtiva visando a maior competitividade, qualidade e variedade de seus produtos e baixo custo, garantias de manu- tenção em um mercado marcado pelo processo de globalização.

\section{Universo empírico da pesquisa}

Franca, localizada na região nordeste do Estado de São Paulo, é o maior polo produtor de calçados masculinos do país e abriga cerca de 750 indústrias que geram aproximadamente $25 \mathrm{mil}$ empregos. A produção, em 2009, foi em torno de 25 milhões de pares 7,8.

Nos anos de 1990, o processo de reestruturação produtiva impulsionado pelo aquecimento da competição intercapitalista foi intensificado entre as indústrias do município, que passaram a experimentar novas maneiras de organizar a produção e o trabalho, em boa medida, inspiradas no modelo japonês.

Como consequência, ocorreram a eliminação de postos de trabalho, o aumento da intensificação do ritmo de trabalho, o aviltamento salarial, o aumento do controle exercido sobre os trabalhadores e a crescente informalidade do emprego.

O pesponto, ou seja, a costura mecânica do calçado que liga as peças de couro formando a parte superior do calçado, conhecida como cabedal, é atividade realizada majoritariamente por mulheres e foi uma das etapas da produção mais atingidas pela reestruturação produtiva, o que levou muitas pespontadeiras a trabalharem fora das fábricas.

O objetivo desta pesquisa foi investigar e estabelecer relações entre as condições de trabalho nas atividades de pesponto em unidades produtivas de calçados de Franca e os problemas de saúde relatados pelas trabalhadoras que as executam.

\section{Percurso metodológico}

A pesquisa, de caráter qualitativo, teve embasamento teórico e metodológico no materialismo histórico dialético e combinou técnicas de pesquisas sociológicas e etnográficas. O principal instrumento de coleta de dados foi a entrevista semiestruturada. Em 2009, foram entrevistadas 30 trabalhadoras, contatadas por intermédio do Sindicato dos Trabalhadores nas Indústrias de Calçados de Franca (STICF). As entrevistas, focadas em história de vida e trabalho, foram gravadas e transcritas na íntegra.

Os critérios determinantes para a inclusão das entrevistadas na pesquisa foram: que as trabalhadoras fossem pespontadeiras, que realizassem tal tarefa há, no mínimo, 12 meses, que estivessem trabalhando em unidades produtivas 
de diferentes portes ou no domicílio e que concordassem em participar do estudo mediante assinatura de Termo de Consentimento Livre e Esclarecido.

Além das entrevistas, a pesquisa associou informações advindas de outras fontes: de observações diretas do processo de trabalho em fábricas, bancas e domicílios; de anotações em caderno de campo; de documentos históricos e dados secundários disponíveis no Museu do Calçado de Franca, no Centro de Referência em Saúde do Trabalhador de Franca (CEREST), no Sindicato da Indústria de Calçados de Franca (SICF), no STICF; de jornais de circulação regional e nacional e de outras pesquisas dedicadas ao tema.

No início dos trabalhos de pesquisa, foi realizada documentação fotográfica para registro das condições dos ambientes de trabalho e para seu uso como técnica projetiva: as fotos, ao serem apresentadas às trabalhadoras, auxiliaram na elaboração das descrições de seus postos de trabalho. A visualização das imagens estimula elementos da memória que permitem o surgimento de novas informações pertinentes à pesquisa e permite também que o entrevistado comente elementos registrados nas fotografias, o que auxilia o entendimento do pesquisador sobre $o$ assunto estudado 9 .

As entrevistas que totalizaram aproximadamente 60 horas de gravação e 120 horas de transcrição foram realizadas nos domicílios das trabalhadoras, às quais foi garantido o anonimato e, para tanto, adotados nomes fictícios. À medida que as entrevistas eram transcritas, foi sendo feito um levantamento prévio dos depoimentos e organizadas as informações relativas ao objeto de estudo. De posse do material obtido nas entrevistas e demais fontes, foi realizada sua organização e categorização, obedecendo aos objetivos da pesquisa. As narrativas escolhidas foram separadas por temas que contemplavam os objetivos, as questões norteadoras da pesquisa e as categorias analíticas. A reconstituição do processo de trabalho foi realizada de forma a articular teoria e empiria em torno das questões referentes ao trabalho e à saúde das trabalhadoras.

Esta pesquisa foi aprovada pelo Comitê de Ética do Hospital das Clínicas da Faculdade de Medicina de Ribeirão Preto, Universidade de São Paulo (FMRP/USP).

\section{O trabalho das pespontadeiras na indústria de calçados de Franca}

O processo de produção do calçado é organizado em torno de cinco operações principais: a modelagem, o corte, o pesponto, a montagem e o acabamento. Esta pesquisa se ateve à análise do trabalho no pesponto. Na seção de pesponto, que inclui também a preparação das peças (dobradura e colagem) há predomínio do trabalho feminino. O pesponto é realizado tanto no interior das fábricas, quanto nas bancas e no trabalho domiciliar. Em Franca, a maior parte do pesponto é realizada em máquinas antigas que não dispensam a qualificação do trabalhador.

Os dados da pesquisa revelaram que há no pesponto uma pormenorizada divisão do trabalho, que atende aos diferentes tipos de costura e busca o aumento da produtividade. Nesta atividade uns são especializados em pregar taloneira, outros em fechar o forro, fechar o lado, fazer costuras de enfeite, pespontar com costura simples ou costura paralela, dentre outras. Inclui também os trabalhos de preparação para o pesponto como dobrar e colar peças, furar, pregar ilhoses etc. Há também uma rígida disciplina, determinada pelo tempo da esteira, que exige da trabalhadora grande atenção, eficiência e rapidez para que dê conta do tempo e do ritmo do processo de trabalho.

"[O tempo] é cronometrado para que a gente faça o par de calçado. Se o serviço passar por você, eles [os calçados] não voltam para trás, é onde a gente roda. É aí que as pessoas sofrem porque cada um tem um jeito de pespontar, uns mais rápidos, outros mais devagar e, na fábrica, você tem que trabalhar no ritmo da esteira e não no seu ritmo de trabalho, porque quem faz o ritmo é ela" (Natália, 22 anos, fábrica de grande porte).

Observou-se ainda que a reestruturação produtiva trouxe novas estratégias de planejamento da produção e alterou a forma da divisão e organização do trabalho no pesponto, assim como o controle sobre o trabalhador. $\mathrm{O}$ trabalho em grupo ou células de produção, que é caracterizado pelo reagrupamento de tarefas antes realizadas individualmente, é uma estratégia eficiente de controle do trabalhador, pois os companheiros do grupo controlam o ritmo de trabalho e a qualidade do produto e, como o pagamento passa a ser realizado pela produção coletiva, é desnecessária a presença de supervisor na seção ${ }^{10}$.

O predomínio de trabalho feminino neste tipo de atividade, que requer destreza e habilidades manuais, é justificado por alguns autores pelo fato de as mulheres terem habilidades específicas e paciência 11, talvez derivadas do treino no universo doméstico com tarefas que exigem acuidade visual, habilidades específicas e agilidade com as mãos; dessa forma, o trabalho feminino foi incorporado ao trabalho industrial em postos de trabalho em que tais requisitos são exigidos para a realização da atividade 12 . 
Para Rezende 11, o capital se valeu dessas especificidades para explorar o trabalho feminino, uma vez que, por se tratar de habilidades adquiridas ao longo do processo de socialização, não foram consideradas como qualificações profissionais.

"Na fábrica é assim: no pesponto tem praticamente só mulher. Na modelagem e no corte é mais homem. Na montagem é praticamente homem e no acabamento varia muito" (Maísa, 35 anos, fábrica de médio porte).

As diferenças de gênero evidenciadas pelas desigualdades existentes entre homens e mulheres representam problema importante nos mercados de trabalho de todo o mundo 13 , e não se caracterizam apenas pelas diferenças biológicas, mas pelas formas de representação na sociedade, pelos arranjos sociais, pelas condições de acesso aos recursos da sociedade e pela história 14.

A divisão sexual do trabalho se constitui socialmente nas relações de gênero, de classe e das práticas sociais, sendo caracterizada por uma hierarquia que subordina as mulheres e sua força de trabalho, ou seja, ela "produz e reproduz a assimetria entre práticas femininas e masculinas, constrói e reconstrói mecanismos de sujeição e disciplinamento das mulheres, produz e reproduz a subordinação de gênero e dominação” 15 (p. 16).

De acordo com Brito 16 (p. 200), "a precariedade sempre esteve associada a trabalho feminino, uma vez que, mesmo quando a insegurança, a instabilidade e o desemprego atingem toda a população de trabalhadores, o trabalho masculino tende a estabilizar-se, enquanto o feminino tende a manter-se incerto e irregular".

A subordinação de gênero é manifestada na divisão sexual do trabalho pelas desigualdades existentes como nos salários e na desqualificação das funções femininas 15 .

"Geralmente o homem tem mais vantagem em quase todos os setores, por exemplo, se a gente estiver discutindo um sapato, jeito de fazer, a voz mais pesada é dele" (Júlia, 23 anos, fábrica de médio porte).

"Se tem um cortador e uma mulher que corta, ele ganha mais que ela. Se tem um pespontador homem e uma mulher, se alguém tem que ser promovido, sempre procuram promover o homem" (Dora, 51 anos, banca).

"Tem essa discriminação mesmo, trabalho igual, salário diferente. Eles discriminam, tanto que eu já vi várias placas em fábricas dizendo: 'Não admitimos mulheres' porque a mulher engravida e isso é uma coisa da natureza. É uma discriminação enorme" (Sandra, 40 anos, fábrica de grande porte).

Com relação à organização do processo de trabalho, foi observado que a utilização de es- teiras se dá predominantemente em fábricas de médio e grande porte, onde a produção é maior. Naquelas de pequeno e micro porte, assim como no trabalho domiciliar, a tarefa é organizada em grupos ou realizada individualmente. No último caso, ao pesponto são acrescentadas operações complementares como cortar e queimar linhas e outras atividades de preparação do calçado, o que pressupõe a necessidade de um trabalhador multifuncional, capaz de realizar todo um grupo de tarefas.

"Em casa o serviço do pesponto é mais. Exige mais da gente, porque aqui a gente tem que fazer mais coisas que na fábrica, como a dobração e a cola. Lá a gente já pega pronto. Em casa exige bem mais da gente. Além de ter mais trabalho, a gente tem que ir pegar e levar o serviço" (Beatriz, 59 anos, domicílio).

Quanto às condições de trabalho, uma das queixas apontadas pelas pespontadeiras entrevistadas foi o ruído excessivo produzido pelas máquinas no interior das fábricas e, no trabalho em domicílio, os barulhos produzidos pela máquina de costura e pelo compressor (equipamento responsável pela geração de ar comprimido, necessário ao funcionamento de algumas máquinas).

"O barulho me incomoda muito e acaba dando dor de cabeça porque é aquele monte de máquina funcionando ao mesmo tempo. Tem a máquina de pesponto, o rebatedor de costura, aqueles revólveres da cola, o compressor. Tem hora que eu acho que eu vou ficar louca" (Meire, 23 anos, fábrica de médio porte).

Cabe salientar que a exposição contínua ao ruído pode causar perda auditiva (temporária ou permanente), dores de cabeça, cansaço, dificuldade de atenção e concentração, alterações cardiovasculares, dificuldade em realizar movimentos precisos, desânimo.

Outra queixa comum nos depoimentos foi em relação às altas temperaturas e à falta de ventilação nos ambientes de trabalho, que pode ser causa de fadiga térmica, irritabilidade, alteração da atividade mental 17, desidratação, taquicardia, sonolência, sensação de exaustão.

“É terrível, é muita aglomeração! É muita máquina, é muita gente, aquele monte de material te cercando e a ventilação é pouca. Tem alguns ventiladores, mas (...) ar não chega em você. Junta com aquelas telhas de alumínio... Tem dia que o suor escorre, a roupa chega ensopar de tanto calor. É onde dói mais o corpo, a gente sente mais mal estar" (Natália, 22 anos, fábrica de grande porte).

"Lá é tudo fechado. Nós não sabemos se é dia ou noite, se está chovendo, se o mundo está acabando, você não vê nem a luz do dia. A ventilação é um problema: o ventilador pega em uns, mas 
não pega em outros" (Raquel, 41 anos, fábrica de grande porte).

As condições do ambiente e a insalubridade do trabalho, relatadas pelas trabalhadoras das fábricas de grande porte é também sentida por aquelas que trabalham em seus domicílios: " $O$ calor aqui é demais. Você não imagina o calor que nós sentimos nesse quartinho improvisado" (Flávia, 19 anos, domicílio). "Tem época que o calor é tanto que a gente sai mudando o lugar de trabalhar. Vai trabalhar no quintal, na varanda. A gente fica onde dá para trabalhar melhor. Nesse cômodo com telha de Eternit, não dá para ficar..." (Gabriela, 30 anos, domicílio).

Conforme constatamos, tanto nas fábricas, quanto no trabalho em domicílio, as trabalhadoras estão expostas a ruídos; ao calor; a solventes que fazem parte da composição de insumos, como a cola de sapateiro, tintas e vernizes; ao pó proveniente da raspagem do couro, que tem efeitos irritantes e asfixiantes, e podem originar diversas doenças; além do carregamento de cargas pesadas.

“Eu tenho muita alergia por causa do pó do sapato, do cheiro da cola. O cômodo aqui é muito apertado e o cheiro da cola fica muito forte. Tem noite que eu não consigo respirar por causa da alergia, mesmo porque eu tenho renite e sinusite. Isso dá bastante" (Bianca, 27 anos, domicílio).

"Eu sozinha pego todas as caixas dos 500 ou 600 pares que eu tenho que fazer. É onde me dói. Tem gente que eu mostro minhas mãos e a pessoa não consegue ver nada, mas só eu sei o quanto esses punhos me doem, mesmo parecendo que não tem nada" (Mirian, 22 anos, fábrica de grande porte).

A pressão para o cumprimento de metas e o controle constante exercido sobre os trabalhadores são outros fatores que agravam as condições de trabalho e prejudicam a saúde das trabalhadoras.

“A produção que a fábrica exige é muita. Eu dou conta, mas exige muito do meu corpo. No final do dia eu estou muito cansada. É muita pressão" (Raquel, 41 anos, fábrica de grande porte).

"Não dá prazer em trabalhar, não temos valorização alguma. Às vezes eles mandam você fazer alguma coisa correndo e a gente tem que fazer fora da esteira. Eles não entendem que a gente é humano, que a gente não é máquina. Eles só falam que a gente tem que dar conta, de qualquer forma. A gente não vai ao banheiro para poder dar conta" (Mirian, 22 anos, fábrica de grande porte).

Quando o pesponto é realizado nas bancas ou nos domicílios, pode-se observar outros agravantes, visto que os ambientes de trabalho são mais precários. Nesses locais, a ventilação e iluminação são inadequadas. O maquinário, em ge- ral, é adquirido de segunda mão e, muitas vezes, é proveniente de descarte de fábricas maiores; o mobiliário como bancadas e cadeiras não tem a altura ideal e não apresentam dispositivo de regulagem de altura. Nesse caso, as trabalhadoras improvisam calços e outros artifícios para ajustar a mobília à sua estatura. Cadeiras velhas, mancas, mesas pequenas, maquinário velho, iluminação parca, falta de ventilação, poeira, gases provenientes da cola e outros solventes compõem os ambientes de trabalho que não raramente são instalados dentro da casa, na cozinha, sala e mesmo em quartos de dormir.

"Não é um posto adequado, porque geralmente é dentro de casa, próximo às crianças, à comi$d a "$ (Estela, 27 anos, domicílio).

"Na banca e em casa é mais improvisado. $\mathrm{Na}$ fábrica eu trabalhava em cadeira, aqui eu trabalho em um tamborzinho com uma madeira em cima. Além disso, aqui tem de tudo um pouco, você guarda a bagunça em um cantinho, no outro você coloca as linhas, tem a caixa que tem os restos que sobram que você tem que deixar ali porque se faltar alguma coisa você procura ali antes de ir à fábrica buscar. Prefiro trabalhar na fábrica" (Conceição, 34 anos, banca).

Outro fator que agrava as condições de trabalho são mudanças que passaram a ser cada vez mais frequentes nos modelos de calçados com a reestruturação produtiva. Isso afeta o trabalhador tanto pelo fato de provocar quedas em seu rendimento quanto pelo maior desgaste físico que proporciona 10 .

As pespontadeiras que trabalham no interior das fábricas confeccionando amostras (protótipos dos sapatos para fins de comercialização) e realizando consertos, produzem cerca de 12 pares/dia; a aparente pequena produção deve-se ao fato de esses serviços serem mais demorados e demandarem alta qualificação. As que trabalham nas linhas de produção em fábricas de grande porte participam da confecção de cerca 600 pares/dia, realizando costuras de partes específicas do cabedal.

Diferentemente das trabalhadoras das fábricas, aquelas que trabalham no domicílio ou em bancas se dedicam à costura de todo o cabedal e também a preparação para o pesponto; portanto, o tempo gasto para a produção de um par é muito maior que aquele despendido para a produção de um par feito na fábrica. Nos domicílios ou nas bancas, as trabalhadoras produzem entre $15 \mathrm{e}$ 100 pares/dia, podendo chegar a 300 pares/dia. Tal variação depende do modelo produzido, da quantidade de pedido e da disponibilidade de serviço.

À época da pesquisa, o salário das pespontadeiras variava de $\mathrm{R} \$ 660,00$ a $\mathrm{R} \$ 1.000,00$ pa- 
ra as que desenvolviam suas atividades dentro da fábrica; as pespontadeiras que trabalhavam em grupos recebiam por peça produzida enquanto as que trabalhavam em esteiras recebiam salário fixo. Para as que trabalhavam no domicílio ou em bancas o recebimento mensal variava entre $\mathrm{R} \$ 500,00$ e $\mathrm{R} \$ 1.700,00$ e podia alcançar R\$3.000,00 em épocas de grande produção; via de regra tais trabalhadoras recebiam por peça produzida, cujo par variava de $\mathrm{R} \$ 0,35$ a $\mathrm{R} \$ 7,80$, dependendo do modelo do calçado a ser costurado.

A aparente melhora no rendimento das pespontadeiras que trabalhavam no domicílio ou em bancas se esvai quando são computados os custos com seus encargos trabalhistas, gastos com manutenção de maquinário, de energia e de materiais necessários para a confecção do calçado. A tais custos hão de ser somados outros, de difícil cálculo, como a responsabilidade pela segurança e higiene no trabalho e o fato de o trabalho terceirizado ser sempre acompanhado de prolongamento extraordinário da jornada de trabalho. Assim, o tempo de trabalho e de não trabalho dessas mulheres passa a ser dedicado quase que exclusivamente à fábrica 10 .

A jornada de trabalho de todas as pespontadeiras entrevistadas era superior a oito horas diárias, e as que trabalhavam a domicílio tinham jornadas de trabalho que chegavam a 12 horas, muitas vezes sem descanso nos finais de semana e feriados.

De acordo com Dal Rosso ${ }^{18}$ (p. 31), a jornada de trabalho se expressa, em primeiro lugar pelo componente de duração, "que compreende a quantidade de tempo que o trabalho consome das vidas das pessoas". Para o autor, isso possui muitas implicações, como a interferência na qualidade de vida dos trabalhadores; a definição da quantidade de tempo que esses indivíduos dedicam às suas outras atividades; e o estabelecimento direto de relações entre as condições de saúde, o tipo e o tempo de trabalho.

"Eu entro às 6h45min e saio às 12h00min para o almoço. Volto às 13h00min e saio às 17h30min" (Gisele, 42 anos, microempresa).

“Eu começo às 6h30min e paro para fazer o almoço e almoçar. Volto e trabalho o dia todo. Tem dia que eu trabalho até as 23h30min, meia noite. Trabalho no sábado também e, às vezes, até no domingo. Estando aqui dentro de casa você não fica sem trabalhar" (Fernanda, 55 anos, domicílio).

O prolongamento da jornada de trabalho não provoca "apenas a atrofia da força de trabalho, a qual é roubada de suas condições normais, morais e físicas"; a longa jornada de trabalho "produz a exaustão prematura e o aniquilamento da pró- pria força de trabalho", prolongando "o tempo de produção do trabalhador (...) mediante o encurtamento de seu tempo de vida" 19 (p. 379).

Ao ingressarem no mercado de trabalho, as mulheres por um lado conquistaram relativa autonomia financeira, mas, por outro, ampliaram suas responsabilidades, foram sobrecarregadas de trabalho e passaram a apresentar significativo desgaste em sua saúde, além de alimentarem sentimento de culpa por não conseguirem cumprir adequadamente todas as tarefas de seus lares, incluindo o cuidado dos filhos 20 . O ingresso da mulher no mercado de trabalho não representou sua emancipação; dentre outras coisas, resultou em dupla jornada de trabalho, já que não a livrou dos afazeres domésticos 21 .

A maioria das entrevistadas reclamou da dupla jornada de trabalho: "A mulher tem que cuidar da casa, fazer a janta, tem que lavar, passar, então a gente tem que ficar dividindo com mais a tarefa de casa. Só se você chegasse em casa e não fizesse nada como os homens. Mas como isso é impossivel..." (Priscila, 22 anos, fábrica de grande porte).

Com relação aos problemas de saúde relacionados ao trabalho, as queixas mais frequentes entre as pespontadeiras entrevistadas foram dores nos dedos, nas mãos, nos braços, nos ombros, nos joelhos, nas pernas, nos pés, nas costas e cansaço visual.

"Muitas vezes você está morrendo de dor, você está custando trabalhar, o ombro está doendo, o cotovelo dói, o punho dói, os dedos doem, mas você está aguentando, você está tomando analgésico, porque você precisa trabalhar" (Estela, 27 anos, domicílio).

As queixas de LER/DORT se sobressaíram nos depoimentos. O desgaste provocado pelas longas jornadas, pela repetitividade das tarefas, pela intensificação do ritmo de trabalho e pela pressão sofrida pelas trabalhadoras, é sentido nos músculos, nos tendões e nos nervos.

"Minha mão dói muito e vem doendo o braço. Meu braço está todo dormente. A noite dói tanto que eu tenho que tomar remédio para dormir. Além do problema das mãos, junta o problema emocional, vem depressão, vem tudo. Eu adquiri problema nas mãos por conta do movimento repetitivo do pesponto. Tenho Síndrome do Túnel do Carpo. Eu fiz a cirurgia, só que ela me tirou um pouco das forças das mãos" (Mariana, 41 anos, fábrica de grande porte).

Ao serem acometidos por LER/DORT, os trabalhadores passam a conviver com dificuldades de se relacionar com seu corpo, seus movimentos, agilidade, precisão, destreza. A dor crônica e a limitação física acabam impedindo o trabalhador de executar tarefas rotineiras, de autocui- 
dado, de lazer, o que gera angústia diante do seu estado clínico 22 .

“O pesponto causa a tendinite porque em função do movimento e da posição do braço, ele vai dando problema nesse nervo da mão [referindose à região do punho]. É nele que você começa a sentir a tendinite, porque aí você começa a sentir o formigamento, os adormecimentos. Você não consegue segurar mais nada na mão. A dor nunca para. Eu mal consigo carregar uma bolsa no ombro e aí a gente tem que gastar muito com remédio, com convênio, pagar guia, esperar" (Meire, 23 anos, fábrica de médio porte).

"Por conta das dores da tendinite nos punhos, eu não faço mais nada sozinha aqui em casa. Ontem mesmo caíram dois copos da minha mão. Minha filha tem que me ajudar a fazer almoço. Passar roupas nem se fala. Eo pior é que ninguém acredita, pois eu sou grande e forte. Então acham que eu estou fazendo corpo mole" (Telma, 41 anos, fábrica de grande porte).

O efeito nefasto do trabalho na saúde das pespontadeiras não se limita ao sofrimento do corpo, por vezes insuportável. Ele coexiste com sofrimentos de ordem psíquica que, somados às inadequadas condições de trabalho, tornam as trabalhadoras ainda mais vulneráveis ao adoecimento e evidenciam a desumana exploração do trabalho na feitura do calçado.

“A cabeça dói quando você fica muito nervosa e muito estressada com o serviço. Você deita na cama, não consegue nem ficar deitada, sentada, nem em pé. Eu tomo muito calmante para dormir. Até antidepressivo eu tomo, porque você fica tão nervosa que você entra em depressão. Tem dia que eu choro em cima da máquina porque não vai dando certo. Você fica nervosa e tem que tomar remédio" (Bianca, 27 anos, domicílio).

“Eu me sinto muito estressada por trabalhar muito porque eu já atravessei noites trabalhando sozinha, colando e pespontando. Eu não queria fazer isso mais. Eu estou muito esgotada" (Elisa, 36 anos, domicílio).

“Para os patrões a gente não vale nada. Eles querem só o dinheiro deles no final do mês, não importa quem fez" (Yasmin, 37 anos, fábrica de grande porte).

Os depoimentos das pespontadeiras, por vezes calados por choros que revelaram sua angústia, desespero, sofrimento, medo, revolta, raiva e descrença são provas de que "o trabalhador se torna mercadoria tão mais barata quanto mais mercadorias cria. (...) a valorização do mundo das coisas aumenta em proporção direta à desvalorização do mundo dos homens" 23 (p. 148).

"Eu acho que há muito tempo eu estou esquecida, porque minha vida é do trabalho para casa, da casa para o serviço. Então eu acho que para muitos, eu não existo na sociedade" (Valentina, 46 anos, fábrica de grande porte).

"É raríssimo eu fazer alguma coisa que não seja trabalhar" (Elisa, 36 anos, domicílio).

Como pode ser observado, o tempo dedicado ao trabalho ocupa parte significativa da vida daquelas trabalhadoras. A forma imposta pela organização do trabalho rouba-lhes o tempo livre, aquele que deveria ser destinado ao descanso, ao lazer, às inúmeras atividades relacionadas à vida familiar, dentre elas os cuidados com os filhos, com o marido, com os idosos, com a saúde.

"As pessoas para trabalhar em casa têm que pensar muito. Têm que ver se não têm outros meios, se não têm outra coisa para fazer. É muito difícil, é cansativo e você tem que ter uma estrutura mental, psicológica, física muito grande para poder trabalhar em casa. Se não tiver garra, força, não consegue. Eu só vivo para trabalhar, não faço mais nada além de trabalhar" (Estela, 27 anos, domicílio).

Os dados obtidos indicam que a intensificação e a precariedade do trabalho afetam tanto as trabalhadoras formalmente empregadas nas fábricas quanto as que desenvolvem suas atividades nas bancas e a domicílio. No entanto, observou-se que houve maior exploração das trabalhadoras que desenvolviam suas atividades no domicílio, dado que as empresas, ao transferirem o trabalho para fora de seus muros, também transferem eficientemente seus problemas, ou seja, desresponsabilizam-se de todo e qualquer direito social e transferem para a trabalhadora a incumbência e a responsabilidade de zelar pelas próprias condições de higiene e segurança do trabalho e dos que com ela vivem e trabalham. Tal modalidade de trabalho pune também a trabalhadora à medida que sobre ela recaem os efeitos da flutuação do mercado, pois a necessidade desse tipo de trabalho pelas empresas é marcada pela sazonalidade. Além disso, o trabalho no domicílio também cria ou favorece condições para a exploração do trabalho de crianças, ainda que sob o pretexto de "ajuda" às suas mães 24 .

No que se refere à saúde das trabalhadoras, o trabalho realizado fora das fábricas apresenta mais um agravante: por se encontrar disperso na malha urbana do município e ser realizado no interior das residências, onde é difícil o acesso à fiscalização, as trabalhadoras ficam mais vulneráveis às condições insalubres que esses locais de trabalho possam apresentar.

Outro aspecto importante a ser considerado é que o repasse do trabalho pelas fábricas aos trabalhadores não é regular, o que torna mais difícil o estabelecimento de nexos causais entre o trabalho e os problemas de saúde apresentados pelos trabalhadores, fato reportado por Minayo- 
Gomez \& Thedim-Costa ${ }^{4}$ (p. 23), que advertem que “...como frequentemente as doenças originadas no trabalho são percebidas em estágios avançados torna-se difícil, sob essa ótica, identificar os processos que as geraram, bem mais amplos que a mera exposição a um agente exclusivo".

$\mathrm{O}$ que se pode verificar é que com a ampliação do trabalho no domicílio, "assistimos à retomada de um recurso comum ao início do capitalismo industrial, mostrando a imensa capacidade de o capital recuperar antigas relações de trabalho para assegurar sua reprodução ampliada" 10 (p. 424).

\section{Considerações finais}

A partir da década de 1990, acompanhando a tendência percebida em outros ramos industriais, a indústria de calçados acirrou o processo de reestruturação produtiva. Tal processo, que tinha por meta aumentar a competitividade dos produtos mediante a redução dos custos de produção, a melhoria da qualidade e ao aumento da produtividade, implicou mudanças de ordem tecnológica e organizacional e em crescente transferência da produção para fora das fábricas, via terceirização. A indústria francana de calçados registrou esse mesmo movimento, o que resultou em eliminação de postos de trabalho, intensificação do ritmo de trabalho, em sobrecarga e em maior precariedade das condições e relações de trabalho, com repercussões na saúde dos trabalhadores, como atesta esta pesquisa.
Constata-se que as trabalhadoras da indústria de calçados de Franca, a exemplo de outras categorias de trabalhadores no país, vivenciam um cotidiano laboral marcado pela intensificação e precariedade de suas atividades, que resultaram em maior desgaste físico e mental, no incremento da probabilidade de acidentes causadores de incapacidade, na diminuição ou ausência de contratos formalizados de emprego, no aumento do trabalho no domicílio, subcontratado, terceirizado.

A reconstituição e a análise do processo de trabalho das pespontadeiras empregadas na produção de calçados possibilitaram o conhecimento de como se processa o controle e o desgaste dessas trabalhadoras no momento da produção, além de demonstrar que não é possível analisar a saúde do trabalhador apenas pela observação de sua exposição a agentes físicos, químicos ou biológicos presentes nos ambientes de trabalho. Para isso há de se levar em conta a forma de divisão e organização do trabalho, o aparato tecnológico, o ritmo ditado, a duração da jornada, os salários, as relações de trabalho adotadas entre outros mecanismos que fazem parte do novo padrão de acumulação do capital em vigência.

Longe de se tratar de caso isolado, o estudo possibilitou a compreensão de uma problemática vivenciada por muitos, pois os depoimentos das trabalhadoras, apesar de traduzirem experiências individuais, remetem à experiência coletiva vivida por grande parte dos trabalhadores na contemporaneidade.

\section{Resumo}

Este artigo é fundamentado em pesquisa que teve como objetivo estabelecer relações entre as condições de trabalho na indústria de calçados de Franca, São Paulo, Brasil, e os problemas de saúde relatados pelas trabalhadoras especializadas na atividade de pesponto (costura mecânica). A pesquisa de caráter qualitativo foi embasada teórica e metodologicamente no materialismo histórico-dialético e combinou técnicas de pesquisas sociológicas e etnográficas. A coleta de dados se deu por entrevistas gravadas, focadas na história de vida e trabalho, na observação sistematizada do processo de trabalho, na consulta a documentos históricos e na produção imagética. A análise dos dados permitiu compreender os efeitos do trabalho na saúde das trabalhadoras empregadas nas fábricas e no domicílio, que vivenciam processos laborais precários que se objetivam na intensificação e ampliação da jornada de trabalho, na cobrança por metas de produção, na insegurança do emprego e nos ambientes de trabalho insalubres.

Saúde do Trabalhador; Trabalho Feminino; Condições de Trabalho 


\section{Colaboradores}

T. J. Prazeres contribuiu na concepção do projeto de pesquisa, revisão bibliográfica, coleta de dados, análise e interpretação dos dados e redação do artigo. V. L. Navarro colaborou na redação do artigo, revisão crítica do conteúdo intelectual, aprovação da versão final do artigo.

\section{Referências}

1. Antunes R, Alves G. As mutações no mundo do trabalho na era da mundialização do capital. Educação \& Sociedade 2004; 25:335-51.

2. Antunes R. Os sentidos do trabalho: ensaio sobre a afirmação e a negação do trabalho. São Paulo: Editora Boitempo; 1999.

3. Hirata H. Nova divisão sexual do trabalho: um olhar voltado para empresa e a sociedade. São Paulo: Editora Boitempo; 2002.

4. Minayo-Gomez C, Thedim-Costa SMF. A construção do campo da saúde do trabalhador: percurso e dilemas. Cad Saúde Pública 1997; 13 Suppl 2:21-32.

5. Carloto CM. Adoecimento no trabalho, as mulheres na categoria de asseio e limpeza. Serviço Social em Revista 2003; 6(1). http://www.uel.br/revistas/ ssrevista/c_v6n1_cassia.htm (acessado em 15/ Mar/2009).

6. Lancman S. Psicodinâmica do trabalho. In: Cavalcanti A, Galvão C, organizadoras. Terapia ocupacional: fundamentação e prática. Rio de Janeiro: Editora Guanabara-Koogan; 2007. p. 271-7.

7. Associação Brasileira das Indústrias de Calçados. Polos produtores 2008. http://www.abicalcados. com.br/polos-produtores.html\&est=3 (acessado em Set/2008).

8. Sindicato das Indústrias de Calçados de Franca. Resenha estatística 2010. http://www.sindi franca.org.br/downloads/Resenha\%20Estat\% C3\%ADstica\%20Setembro\%202010AA.pdf (acessado em Nov/2010).

9. Collier Junior J. Antropologia visual: a fotografia como método de pesquisa. São Paulo: EPU; 1973.

10. Navarro VL. A indústria de calçados no turbilhão da reestruturação. In: Antunes R, organizador. Riqueza e miséria do trabalho no Brasil. São Paulo: Editora Boitempo; 2006. p. 387-424.

11. Rezende VD. Anônimas da história: relações de trabalho e atuação política de sapateiras entre as décadas de 1950 e 1980 (Franca-SP) [Dissertação de Mestrado]. Franca: Faculdade de História, Direito e Serviço Social, Universidade Estadual “Júlio de Mesquita Filho"; 2006.

12. Delgado MBG. Terceirização e trabalho feminino. In: Martins HS, Ramalho JR, organizadores. Terceirização: diversidade e negociação no mundo do trabalho. São Paulo: Editora Hucitec; 1994. p. 112-22.

\section{Agradecimentos}

As autoras agradecem ao Sindicato dos Trabalhadores nas Indústrias de Calçados de Franca e Região, pelo apoio recebido, às trabalhadoras que se dispuseram participar da pesquisa e à FAPESP, pela concessão de bolsa de mestrado à primeira autora (processo no. 2008/5189-0).

13. Observatório Brasil da Igualdade de Gênero. Boletim mulher e trabalho. http://www.oitbrasil.org. $\mathrm{br} /$ topic/gender/doc/crisemulheres_10.pdf (acessado em Fev/2010).

14. Louro GL. Gênero, sexualidade e educação: uma perspectiva pós-estruturalista. Petrópolis: Editora Vozes; 2010.

15. Souza-Lobo E. A classe operária tem dois sexos. São Paulo: Editora Brasiliense; 1991.

16. Brito JC. Enfoque de gênero e relação saúde/trabalho no contexto de reestruturação produtiva e precarização do trabalho. Cad Saúde Pública 2000; 16:195-204.

17. O calor excessivo no ambiente de trabalho. Infoseg 2007; (10). http://www.gruporacco.com.br/info seg/Infoseg_Edicao10_calor_excessivo_ambien te_trabalho.pdf (acessado em Mai/2009).

18. Dal Rosso S. Jornada de trabalho: duração e intensidade. Ciênc Cult (São Paulo) 2006; 58:31-4.

19. Marx K. O capital: crítica da economia política. São Paulo: Nova Cultural; 1996.

20. Cabral F, Diaz M. Relações de gênero. In: Secretaria Municipal de Educação de Belo Horizonte/Fundação Odebrecht, organizadores. Cadernos afetividade e sexualidade na educação: um novo olhar. Belo Horizonte: Editora Rona; 1998. p. 142-50.

21. Dedecca CS. Tempo, trabalho e gênero. In: Costa AA, Oliveira EM, Lima MEB, Soares V, organizadoras. Reconfiguração das relações de gênero no trabalho. São Paulo: CUT Brasil; 2004. p. 21-52.

22. Carrijo DCM, Navarro VL. LER e planos de demissão voluntária: trajetórias de dor e sofrimento entre bancários. Cad Psicol Soc Trab 2009; 12:157-71.

23. Marx K. Trabalho alienado e superação positiva da autoalienação humana (manuscritos econômicos e filosóficos). In: Fernandes F, organizador. Marx/ Engels: grandes cientistas-história. São Paulo: Editora Ática; 1989. p. 146-81.

24. Navarro VL. O trabalho e a saúde do trabalhador da indústria de calçados. São Paulo Perspect 2003; 17:32-41.

Recebido em 27/Jan/2011

Versão final reapresentada em 20/Jun/2011

Aprovado em 19/Jul/2011 